\title{
Obtaining Antianemic Preparations and Their Use in Animal Husbandry
}

\author{
L. Japaridze, Ts. Gabelia, E. Salukvadze, N. Salvashvili, N. Osipova, T. Kvernadze
}

\begin{abstract}
Research goal was obtaining of antistress, ecologically clean preparation with high bio-accessibility (bio-digestibility) and low toxicity intended for oral administration, and determination of prospects of its use in the area of live-stock farming (namely pig breeding). Manufacturing method of mentioned preparation is elaborated, which foresees: the use of freshly-prepared iron carbonate paste synthesized via interaction of $\mathrm{FeCl} \cdot 4 \mathrm{H} 2 \mathrm{O}$ and $\mathrm{NaHCO3}$ as a source of main active component - iron (II); interaction of iron carbonate and cobalt chloride with complex formation with monosaccharide D-fructose having hemo-stimulating properties; concentrating of complex solutions up to syrup consistency; its extraction from reaction area in the free state using alcohol-ether mixture, its treatment with acetone, ether, and drying in vacuum conditions; infriction of complex mixtures containing certain quantities complexes of $\mathrm{Fe}(\mathrm{II})$ with fructose, $\mathrm{Co}$ (II) with fructose and a nature clay "clay-Askana"- (through ultrasonic material dispersion);; preparation of water suspension, its drying, grinding, manufacturing of solid form of preparation for oral administration. The preparation manufactured by mentioned method contains (in mass \%): ligand D-fructose 24,2-29,0; iron (II)- 7,5-9,0; cobalt (II)- 0,0007; natural Askan-clay 68,3-62,0. The offered method provides getting of highly digestible, functional targeted product with maximum content of $\mathrm{Fe}(\mathrm{II})$. Therapeutic and preventive efficiency of manufactured preparation was tested on animals under study, namely on newborn piglets (toxicity of preparation was preliminary tested on laboratory white rats). Experiment result was expressed in getting rid of complications (iron deficiency anemia, diarrhea-dyspepsia) caused by stress factors related to termination of breast feeding of piglets and food change, as well as in their normal growth and development, normal blood chemistry values and live weight gain.
\end{abstract}

Index Terms - synthesis, complex, anemia, stress, piglets, bentonite, medical and preventive, preparation, livestock farming.

\section{INTRODUCTION}

Metal deficiency anemia in animals is caused by deficit of indispensable microelement of vital importance - iron. Iron deficiency anemia in newly-born piglets is of newly-born piglets and quantity of microelements delivered with mother's milk. Due to iron deficiency takes place functional disturbance of hematogenic (blood-forming) organs, there is observed the low level of hemoglobin and erythrocytes, vulnerability towards different diseases (diarrhea, body dehydration etc.). Against the background of predetermined by significant difference between growth rates

anemia diseased piglets experience development of immunodeficiency, suppression of erythropoiesis, takes place development of secondary diseases of digestive, breathing and other organs. Based on the abovementioned it can be said that anemia is a general pathological process of many body organs and system as a whole. As a result pig-breeding branch experiences significant economic damage. In the major part of large pig-farming enterprises pig anemia reaches $100 \%$, while mortality index attains 10-15\% [1]-[5].

Based on the above mentioned it is topical to offer a preparation for pig-breeding branch, which will supply animals with additions containing biologically active microelements, aminoacids, hydrocarbons, vitamins etc. under conditions of intensive growth and metabolic processes developing with speed-limit in organism that is characteristic for pigs.

Use of non-traditional natural mineral additions, as the cheap source of calcium, phosphorus, silicium, magnum and other indispensable micro- and macroelements easily digestible for animals is especially important. Various adsorbents, including natural minerals - zeolites, glauconites, bentonites, marls etc., are added to animal ration with a mentioned purpose. Priority is always given to food additions prepared on the basis of cheap, local natural raw materials. Research goal was the manufacturing of antianemic preparation containing biogenic microelements $\mathrm{Fe}$ (II) and Co(II), hemo-stimulating organic compound D-fructose and natural mineral, bentonite-"clay-askana" used as an adsorbent, as well as its testing in live-stock farming (pig-breeding) for treatment and prevention of stress conditions related to termination of breast feeding of store (young) pigs.

Separation piglets from mother is the most critical moment of piggies' life - from the birth till a killing. In case of early termination of breastfeeding period (26th day from the birth) two stress-factors - separation from mother breast and food change have significant negative impact on animals. The mentioned negative development may cause recurrence of iron deficiency anemia (that was no more registered after two-times injection of iron-containing injection solution to prenursery pigs). There are frequent manifestations of complications in functioning of gastrointestinal tract (dyspepsia-diarrhea). As a result takes place deterioration of general physical-physiological and blood chemistry values of animals [6]-[13].

\section{EXPERIMENTAL PART}

L. Japaridze, Ts. Gabelia, E. Salukvadze, N. Salvashvili, N. Osipova, T. Kvernadze, Georgia
Manufacturing of medical and preventive preparation 
against animal anemia foresaw synthesis complexes of Fe(II) and $\mathrm{Co}$ (II) with fructose separately, under different temperature conditions, as a result of interaction of corresponding salts and D-fructose; infriction of mixture containing certain quantities of obtained complexes (through ultrasonic material dispersion) with bentonite "clay-askana" water suspension paste, drying of obtained product, grinding, and manufacturing of solid form of preparation for oral administration (Table 1)

It is noteworthy that the yield of complex $\mathrm{Fe}(\mathrm{II})$ fructose obtained as a result of interaction of $\mathrm{FeCl} 2 \bullet 4 \mathrm{H} 2 \mathrm{O}$ (used as iron source) and D-fructose is low and equals to $74,34 \%$. $25,66 \%$ of total iron quantity is in oxidized Fe(III) condition [14].

Table 1.

\begin{tabular}{|c|l|c|}
\hline \multicolumn{3}{|c|}{ Antianemic preparat for oral administration, mass. \% } \\
\hline \multicolumn{1}{|c|}{ Preparative form } & \multicolumn{1}{|c|}{ Component } & Content \\
\hline \multirow{4}{*}{$\begin{array}{c}\text { Preparation for oral } \\
\text { administration }\end{array}$} & Fe(II)-Fructose & $15.75-31.6$ \\
\cline { 2 - 3 } & D- Fructose & $12.0-24.1$ \\
\cline { 2 - 3 } & Fe(II) & $3.75-7.5$ \\
\cline { 2 - 3 } & Co(II)- Fructose & 0,28 \\
\cline { 2 - 3 } & D- Fructose & 0,21 \\
\cline { 2 - 3 } & Co(II) & 0,07 \\
\cline { 2 - 3 } & Natural Ask an-chy & $68.2-36.5$ \\
\hline
\end{tabular}

It is known that $\mathrm{Fe}(\mathrm{III})$ ions in contradistinction from $\mathrm{Fe}$ (II) ions are characterized by low bio-accessibility (bio-digestibility) [15]. With the purpose of preparation targeted product with a maximum content of $\mathrm{Fe}(\mathrm{II})$, there is elaborated a method, which foresees the use of newly prepared FeCO3- as the iron source.

FeCO3 was obtained through interaction of hot saturated solutions of $\mathrm{NaHCO} 3$ and $\mathrm{FeCl} 2.4 \mathrm{H} 2 \mathrm{O}-$, under conditions of constant stirring. Reaction runs with emission of gas (CO2). By means of decantation water is removed from the deposit formed after sedimentation. Afterwards it is washed thoroughly first with flowing water, and then by distilled water up to removal of chlorine ions. As a result, green-colored iron (II) carbonate is obtained, which is kept under water layer (in order to get rid of oxidation of bivalent iron ions into trivalent ones).

Studies related to determination of medical and preventive efficiency of preparation manufactured according to abovementioned method and in regard to weight change of animals being investigated was conducted in private pig-breeding farm located in Zahesi Village (farmer G. Tsiklauri), on 29 store pigs of three nests (Table 2).

Table 2.

Impact of preparation manufactured according to offered way on live weight of young pigs (20-120 days), I - preparation with 7.5-9.0\% content of $\mathrm{Fe}(\mathrm{II}), \mathrm{n}=12$, II - preparation with $3.75-7.5 \%$ content of Fe(II), n=12; III - control group, $\mathrm{n}=5$

\begin{tabular}{|c|c|c|c|c|c|c|}
\hline \multirow{3}{*}{ Group } & \multicolumn{7}{|c|}{ Pigs age,days } \\
\cline { 2 - 7 } & 20 & 30 & 40 & 50 & 60 & 120 \\
\cline { 2 - 7 } & \multicolumn{7}{|c|}{ Live weight, kg. } \\
\hline I & $4.50 \pm 0.20$ & $7.30 \pm 0.25$ & $9.55 \pm 0.40$ & $13.22 \pm 2.42$ & $16.85 \pm 2.29$ & $100.20 \pm 3.50$ \\
\hline II & $4.90 \pm 0.30$ & $7.80 \pm 0.35$ & $9.80 \pm 0.45$ & $13.58 \pm 2.50$ & $17.3 \pm 2.40$ & $102.0 \pm 3.10$ \\
\hline III & $4.00 \pm 0.30$ & $6.80 \pm 0.40$ & $8.00 \pm 0.45$ & $12.50 \pm 2.45$ & $15.80 \pm 2.50$ & $98.45 \pm 2.80$ \\
\hline
\end{tabular}

On the basis of the agreement biochemical studies of blood samples were carried out in the laboratory of the Institute of Veterinary Medicine at Georgian Agrarian University (Table 3).

Here should be noted that the preparation was primarily tested on toxicity in laboratory conditions, on 20 white rats. It was established that preparation with $3,75-9,0 \%$ content of iron (II) is non-toxic.

Table 3

Relative efficiency of antianemic preparation on biochemical indiceof store (young) pigs, preparation with $7.5-9.0 \%$ content of $\mathrm{Fe}(\mathrm{II}), \mathrm{n}=12 ; \mathrm{I}-$ preparation with $3.75-7.5 \%$ conten of $\mathrm{Fe}(\mathrm{II}), \mathrm{n}=12 ;$ III-control group, $\mathrm{n}=5$

\begin{tabular}{|c|c|c|c|c|}
\hline \multirow{2}{*}{ Group } & \multicolumn{4}{|c|}{ Age, days } \\
\cline { 2 - 5 } & 20 & 30 & 40 & 50 \\
\hline \multicolumn{5}{|c|}{ hem oglobin in the blood, g1 } \\
\hline I & 96,5 & 101,3 & 109,6 & 112,2 \\
\hline II & 102 & 109,1 & 118 & 120,5 \\
\hline III & 82,3 & 84,3 & 86,1 & 88,3 \\
\hline \multicolumn{5}{|c|}{ Erythrocytes in the blood, 10121} \\
\hline I & 72 & 7,4 & 7,7 & 7,9 \\
\hline II & 7,5 & 7,8 & 8,1 & 8,5 \\
\hline III & 5 & 5,3 & 5,4 & 5,6 \\
\hline \multicolumn{5}{|c|}{ Iron(II) in the blood, mkmoll } \\
\hline I & 25,8 & 26 & 26,5 & 26,8 \\
\hline II & 27,2 & 28,5 & 27,9 & 28,5 \\
\hline III & 19,5 & 19,6 & 20,3 & 22,6 \\
\hline
\end{tabular}

Experimental piglets were divided into three groups according to analogue principle for testing of manufactured preparation. With the purpose of preparation selection 20-day piglets were fed (along with mother's milk) once a two days by $0,25-0,5$ grams of preparation dissolved in water (along with 250 grams of liquid food). Starting with 26th day they were nourished everyday with 0,5-1,0 gram per 450 grams of food in the form of solid addition. Food addition for I group of pigs (12 piggies) contained 7,5-9,0\% of elementary iron, II group (12 piggies) $-3,75-7,5 \%$, while in the food for III group of animals ( 5 piglets) didn't contain any additions.

\section{RESULTS AND DISCUSSION}

As a result of systematic observations over testing animals there were established that antianemic preparation has a positive impact on animals, and there was no negative development, in particular, no expected deterioration of general physical-physiological condition and blood chemistry values caused by stress-factors related to termination of breastfeeding period period (Tables $1,2,3$ ).

The reasons for high therapeutic and prophylactic effect of the developed product are:

- chelate complex with high content of indispensable microelement - Fe(II) with hemo-stimulating compound D-fructose [16]-[17];

- a complex of cobalt with D-fructose, which is a kind of ultra-component that increases the availability (assimilation) of the complex of iron (II) with D-fructose [18];

- Natural bentonite clay - "clay-askana" - local, ecologically clean, non-toxic product, thanks to which the antianemic preparation acquires the ability of double, parallel action hemo-stimulating metal complexes fill a deficiency of trace elements in the body, and "clay-askana" regulates the work of 
the gastrointestinal tract, due to high adsorption, catalytic and prolonging properties. At the same time, it will provide gradual, planned release of microelement complexes from clay surface (which is naturally released from organism), and eliminates or reduces to the minimum a side effect permanently accompanying anemia [19];

- Ultrasonic treatment of bentonite clay and a metal-complex-containing system - Ultrasonic dispersion of clay particles in an aqueous suspension to nanosize at a frequency of $22 \mathrm{kHz}$ helps to increase the bioavailability of the antianemic preparations. The specified method (ultrasonic dispersion) is used to improve the pharmacological and therapeutic drugs of and is considered as a new promising direction in medicine [20]-[27].

Manufactured preparations is kept in a dark, hermetically sealed vessel. Medical and preventive composite preparation for metal deficit has to contain 7,5-9,0\% of iron (II). At other iron concentration takes place the correction of mentioned content.

According to studies carried out using adsorption-desorption infrared-spectrophotometric, processes, thermographic, complexonometric titration, photometric analysis and other physical and chemical methods there was shown that synthesized iron-fructose complex contains maximum quantity of bivalent iron. Adsorption of metal complexes on the clay surface is of physical nature that predetermines prolonging properties of preparation. According to studies carried out on rotation viscosimeter Reotest- 2 in the $\mathrm{pH}=2,5-3,0$ range (acidity of gastric juice of store pigs) the offered preparation meets the requirements applied to reological and structure-forming parameters of medicinal products.

\section{CONCLUSIONS}

The antianemic medical and preventive preparation with $3,75-9,0 \%$ content of iron(II) is not toxic, it is characterized by hemo-stimulating-antistress properties that provides stable live weight gain of store pigs in comparison with control analogues (Table 2). As is seen from the Table, the preparation with $7,5-9,0 \%$ content of $\mathrm{Fe}(\mathrm{II})$ is the optimal one.

\section{REFERENCES}

[1] Mikhailova O.A., Tendencies of the Word Swine breeding development. Herald of Agrarian Science, 2018, pp. 36-45.

[2] Bushev A.V., Anemia in young pigs. Bushev A.V., Ten E.V., 2007, "Farm livestock veterinary", 2003, no.10, pp. 45-49 (in Russian).

[3] Nikoladze M.G., Diagnostics and prevention of pigs anemia and immune deficiency, Abstract of diss. of cand. of veterinary sciences, 2003,Vitebsk, 19 p. (in Russian).

[4] Biryukov M.V., Iron deficiency anemia of pigs, Svinovodstvo (pig breeding), 2013, no. 5, pp. 45-49 (in Russian).

[5] Kairov V.P., Growth and development of early weaned pigs under action of biologically active agents (additions), Herald of Gorky State Agrarian University, 2010, 47, no. 1, pp. 63-67.

[6] Avilov Ch.K. Impact of stress-factors on resistance of pig organism, Veterinary of farm animals, 2006 no. 6 , 46-47(in Russian).

[7] Barannikov V.A.. Live weight dynamics and growth intensity of pigs as a result of use of antistress preparations, Proceedings of Kuban State Agrarian University, 2012, 1, 39, 90-92 (in Russian).
[8] Kopteva Yu.S. Metabolism and productivity of store pigs when using probiotic complex under conditions of industrial technology, Abstract of diss. of cand. of biological sciences, 2011, (in Russian).

[9] Lamarin A.A., Pig diseases, Lamarin A.A., Bolocky I.A., Barankov A.I, Reference book. Teaching aid, SPb., Lan, 2008, 640 p. (in Russian).

[10] Khodyreva I.A., Sadomov N.A, Store pigs intestinal micro-biocenosis correction using the preparations of microbiological synthesis, Belarusian State Academy of Agriculture, Gorky, Mogilev district, Republic of Belarus. 2013, pp. 15-20 (in Russian).

[11] Kokorev V.A., Optimization of mineral nutrition of farm animals. Zootechnia, 2013, no. 7, pp. 12-16 (in Russian).

[12] Shulaev G.M., Dobry V.N., Bioplexes of microelements in composition of premixes for store pigs, Svinovodstvo (Pig breeding), 2003, no.6, pp. 30-34 (in Russian).

[13] Ts. Gabelia, L. Japaridze, E. Salukvadze, L. Kashia, S. Urotadze. Determination of $\mathrm{Fe}(\mathrm{II}) / \mathrm{Fe}$ (III)-ions ratio in the iron-fructose complex, Bulletin of Georgian National Academy of Sciences, 2009, vol. 35, no. 1, pp. 36-39 (in Georgian).

[14] Stuklov N.I., Semyonova E.N. Treatment of iron deficiency anemia, what is more important, efficiency or tolerability? "Journal of International Medicine", 2013, vol. 2, no. 1, pp. 47-55.

[15] Gabelia Ts., Japaridze L., Salukvadze E., Kashia L., Urotadze S. Synthesis and study of iron (II)-fructose complex, Bulletin of Georgian National Academy of Sciences, chemical series, 2008, vol. 34, no. 4 , pp. 401-404 (in Georgian).

[16] Salukvadze E., Japaridze L., Gabelia Ts., Lomtadze O. Antianemic preparation on the basis of chelate complex of metals and natural alumosilicates, Materials of the international conference "chemistry of coordination compounds - topical problems of analytical chemistry", 16-17 November, 2017, Baku, pp. 56-57 (in Russian).

[17] Gabelia Ts., Japaridze L., Salukvadze E., Urotadze S. Method for medication manufacturing on basis of Askan-clay, GE P 2014, 6144 B (in Georgian).

[18] Gabelia Ts,, Japaridze L., Salukvadze E., Kashia L., Ebralidze K. Study of reological properties of Co-fructose-Askangel, Herald of Georgian National Academy of Sciences, chemical series, 2009,vol. 35, no. 3, pp. 337-339 (in Russian).

[19] Japaridze L., Gabelia Ts., Salukvadze E., Osipova N., Kvernadze T., Ebralidze K. Obtaining and study of modified Askan clay, Bulletin of Georgian National Academy of Sciences, chemical series, 2017, vol. 43, no.1, pp. 93-96 (in Georgian).

[20] Coffey Rebecca 20 Things You Didn't Know About Nano-technology, Discover, 2012, August, 31, 6.

[21] Laurence, Jeremy, Scientists develop nanoparticle method to help tackle major diseases, 2012, (18 November) DOI:10.1038/nnano.2012.212.

[22] Japaridze L., Gabelia Ts., Salukvadze E., Osipova N., Kvernadze T., Lomtadze O. Iron Carbonate synthesis Method Aimed at obtaining Antianemic Preparation, Materials of 5th International Conference "Nanotechnologies", 2018, Tbilisi, pp. 80-81.

[23] Japaridze L., Gabelia Ts., Salukvadze E., Lomtadze O. Investigation of metal-complex compositions by the metal-indication method, Materials of the international conference Chemistry of coordination compounds: actual problems of analytical chemistry, 2017, 16-17 November, Baku, pp. 56-57.

[24] Beshkenadze I., Gogaladze M., Klarjeishvili N., Lomtadze O., Chagelishvili G., Gogua L. Results of the Study of M2I•MII L2 $\bullet$ nH2O Type Citrates, Annals of Agrarian Science, 2018, 16, pp.7-11 DOI: https://doi.org/10.1016/j.aasci.2017.1202

[25] Beshkenadze I., Chagelishvili A., Gogaladze M., Chagelishvili G., Klarjeishvili N., Lomtadze O., Molodinashvili Z. Study of Physiological Activity of Microelements and Glutamine Acid-containing Chelate Citrates, Annals of Agrarian Science, 2017, 15, pp. 243-246. https://doi.org/10.1016/j.aasci.2017.05.004

[26] Japaridze L.Gabelia Ts., Salukvadze E., Lomtadze O., Kozmanashvili G., Study of Metal-Complexes Composition by Metal-Indicatory Method, Bulletin of the Georgian National Academy of Sciences, 2018, vol.12, no. 2 , pp.45-49.

[27] Japaridze L., Gabelia Ts., .Saluqvadze E., Osipova N., KvernadzeT., Lomtadze O. Iron Carbonate synthesis Method Almed at obtaining Antianemikal Preparation, 5th International Conference "Nanotechnologies", (2018), Tbilisi, 80-81. 